\title{
Ovarian Cancer Surgery - A Population-based Registry Study
}

\author{
PIA LEANDERSSON ${ }^{1}$, GABRIEL GRANÅSEN $^{2}$ and CHRISTER BORGFELDT ${ }^{1}$ \\ ${ }^{1}$ Department of Obstetrics and Gynecology, Skåne University Hospital, Lund University, Lund, Sweden; \\ ${ }^{2}$ Epidemiology and Global Health Unit, Department of Public Health and Clinical Medicine, \\ Umea University, Umea, Sweden
}

\begin{abstract}
Background/Aim: To evaluate ovarian cancer surgery in tertiary centers $(T C)$ and regional hospitals $(R H)$. Patients and Methods: Data from the GynOp registry on patients undergoing surgery for ovarian cancer or borderline tumor from 2013 to 2015 were analyzed. Results: Four TC and 21 RH reported 1,108 cases of surgery with curative intent, 770 cases (69.5\%) in TC and 338 cases (30.5\%) in RH. Out of 458 patients with International Federation of Gynecology and Obstetrics (FIGO) stage IIIC-IV disease 396 (86.5\%) had surgery in TC. We found differences in selection for primary debulking surgery (PDS) $(45 \%$ to $93 \%$, $p<0.001)$ and PDS achieving no residual tumor $(36 \%$ to $70 \%, p<0.001)$ between the four TC. Major complications, re-admissions and re-operation rates did not differ between TC and RH. Conclusion: Tertiary centers perform more extensive surgery compared to regional hospitals without increased frequency of major complications. Tertiary centers display significant differences among patient selection for PDS, as well as achieving no residual tumor.
\end{abstract}

In 2014, 700 Swedish women were diagnosed with ovarian cancer (1). The majority of patients are diagnosed with advanced stages of the disease, reflecting poor outcome. The relative 5-year survival rate in Sweden from 2010 to 2014 was $48 \%$ (2).

The standard-of-care for ovarian cancer is primary debulking surgery (PDS). In advanced stages, International Federation of Gynecology and Obstetrics (FIGO) stage IIIC or IV, an alternative is neoadjuvant chemotherapy (NACT)

This article is freely accessible online.

Correspondence to: Christer Borgfeldt, MD, Ph.D., Associate Professor, Department of Obstet-rics and Gynecology, Skåne University Hospital, Lund University, SE-22185 Lund, Sweden. Tel: +46 461710 00, Fax: +46 46157868, Mobile: +46 709950472, email: christer.borgfeldt@med.lu.se

Key Words: Ovarian, cancer, population, registry, surgery, complication. followed by interval debulking surgery (IDS) after 3 to 4 cycles (NACT-IDS). The difficult question is which patients should be selected for PDS and who should benefit more from NACT-IDS (3). The possible benefits of PDS must be weighed against a considerable postoperative morbidity and mortality (4). In advanced stages, the strongest factor for survival is no macroscopic residual tumor after PDS, as well as IDS (5). This calls for a high level of surgical competence as the surgical procedures needed to achieve complete cytoreduction may include bowel resection, splenectomy, cholecystectomy, lymphadenectomy, peritoneal stripping and/or resection of the ureter or urinary bladder. Patients operated on by surgeons with gynecological oncology subspecialization have superior outcome regarding no residual tumor and survival (6). Concentrating ovarian cancer treatment to tertiary hospitals with high patient volumes significantly improves survival (5).

In 2012, national recommendations proposed a concentration of ovarian cancer treatment to tertiary referral centers (all University Hospitals) in Sweden (7). The National guideline advocates that all adnexal lesions with suspicion of malignancy or patients with risk of malignancy index (RMI) above 200 should be referred to a tertiary center. This has led to an increasing number of patients having surgery by experienced ovarian cancer surgeons (from $49 \%$ in 2008 to $67 \%$ in 2013) (8), but existing guidelines are not mandatory and patients are not always referred to tertiary centers as recommended.

The purpose of this study was to evaluate the current surgical treatment and postoperative outcomes in patients with ovarian cancer reporting to the Quality Registry of Gynecological Surgery, GynOp.

\section{Patients and Methods}

The GynOp registry started to collect data from patients undergoing gynecological surgery in 1997. Since 2004, GynOp includes all major gynecological surgery. The registry is not mandatory and some regions by tradition report to another surgical quality registry. Gynecological clinics in four out of six regions in Sweden, covering 5.03 million people or $52 \%$ of the Swedish population, report to GynOp. 
Sweden has a publically financed health care system. A patient attending a regional hospital $(\mathrm{RH})$ or primary care facility with suspected malignancy should be referred to the tertiary center (TC) in the region; very few patients are referred outside of their region as GynOp is considered to have full population coverage in the regions reporting to the register.

All cases of surgery with curative intent for ovarian, tubal or peritoneal malignancy, including borderline tumor, registered in GynOp from 2013 to 2015 were included in the study.

GynOp collects data from patient questionnaires and doctors' forms. Patients are identified with their personal number in the register. The patient is included in the registry when surgery is scheduled by the operation planner of the clinic and patient's reported data are collected in a preoperative questionnaire online or on paper. The doctor reports data to the registry at admission, surgery and discharge and when the histopathology results arrive. A postoperative patient questionnaire is sent to the patient eight weeks after surgery. The questionnaire includes questions on activities of daily living (ADL) as follows: "How many days after surgery did it take until you were able to perform normal daily activities and get along without more help than before surgery (for example personal hygiene, cook food for yourself, make your bed, walk a short distance)?". Postoperative complications are reported by the patient in the questionnaire and subsequently assessed by the surgeon who will grade the reported complication as major or minor according to the definitions listed below. Surgeons will even report complications to the registry at time of surgery, discharge or in the event of re-admission or re-operation. Major complications include the following: injury to bowel, urinary tract, nerves or vessels that caused re-operation or prolonged hospital stay more than 7 days or persistent physical handicap or death; Bleeding more than $3,000 \mathrm{ml}$ or bleeding that caused re-operation; infection that led to readmission; deep vein thrombosis or pulmonary embolism; any other major complication, i.e. aspiration, allergic shock, myocardial infarct or cerebral complication. Minor complications are defined as: organ injury with less than 7 days prolonged hospital stay; infection leading to antibiotic treatment without re-admission; bleeding less than $3,000 \mathrm{ml}$ with blood transfusion but no reoperation; pain or urinary tract problems with less than 7 days prolonged hospital stay.

Approval for this study was obtained by the Regional Ethics Board, University of Umeå Dnr 2013-155-32M (Supplement to 08120M) Umeå 2013.

Statistical analyses were performed using R (v3.2.3, 2015; R core team, Vienna, Austria).

The Mann-Whitney $U$-test was used for testing differences in distributions between TCs and RHs. Equalities of proportions were tested using Pearson's chi squared test. Comparisons between tertiary hospitals were made using ANOVA, chi squared test or Fisher's exact test. Logistic regression models were constructed to test potential risk factors for complications.

All tests were two-sided and a 5\% level of significance was used.

\section{Results}

From January 2013 through December 2015, 1,108 cases of surgery with curative intent for ovarian, tubal or peritoneal malignancy, including borderline tumors, were registered in Gy-nOp. Four TCs (Linköping, Lund, Umeå and Uppsala University Hospitals) reported a total of 770 (69.5\%) cases and $21 \mathrm{RH}$ reported $338(30.5 \%)$ cases (Figure 1). We decided to include Örebro University Hospital serving a small region with a population of 292,000 in the RH group. RHs are ranked according to case volume; the names of individual hospitals have been omitted for integrity. All TCs had a case volume above 25 per year, while no RH reached above 20 cases per year. Patients' characteristics did not differ regarding age, body mass index (BMI), smoking habits, American Society of Anesthesiologists (ASA) classification or comorbidity between the TC and RH. More patients were staged with advanced disease, FIGO IIIC-IV, in the TC group, $396(51.4 \%)$ vs. 62 patients (18.3\%) in RH; $(p<0.001)$. Pre-operative RMI, an algorithm incorporating menopause status, ultrasound findings and CA-125 level (9), was registered for $471(61.2 \%)$ of TC patients and 243 $(71.9 \%)$ of $\mathrm{RH}$ patients $(p<0.001)$. The proportion of patients with RMI higher than 200, indicating a high risk of epithelial ovarian cancer was higher in TC, $83 \%$ compared with $67 \%$ in RH $(p<0.001)$ (Table I). Table II shows the distribution of FIGO stages in the two groups, with borderline tumors being excluded. Complete information on FIGO stage was available in $88.3 \%$ of TC patients and $54.7 \%$ of RH patients $(p<0.001)$.

Only patients with advanced disease (FIGO stage IIIC-IV) were included in the following analyses on surgical outcome. Out of 458 patients with advanced disease (FIGO stage IIICIV), $396(86.5 \%)$ had surgery in TC and $62(13.5 \%)$ in RH. PDS was performed in a higher proportion of patients in RH than in TC $(80.9 \% v s .66 .9 \%, p<0.05)$. The proportion of patients with no residual tumor after PDS did not differ significantly between TH and RH (54\% vs. 48\%) (Table III). Significant differences were found between the four TCs with PDS performed in $45 \%$ to $93 \%$ of patients and no residual tumor achieved in $36 \%$ to $70 \%$ of PDS patients $(p<0.001)$ (Table IV). For IDS patients, no residual tumor was achieved in $53 \%$ at TC and $25 \%$ at $\mathrm{RH}$. Between the four TCs, residual tumor rates in IDS ranged from $37 \%$ to $68 \%$. None of these differences were significant (Table IV).

More TC patients had non-gynecological additional cytoreductive surgery with $44.9 \% v s .21 \%$ of RH patients $(p<0.001)$ undergoing one or more of the procedures listed in Table V. Colon resection was the most common procedure performed in $33.8 \%$ of TC patients vs. $17.7 \%$ of RH patients $(p<0.05)($ Table V).

The median operation time for PDS was longer in TC; $261.5 \mathrm{~min} v s .148 .5 \mathrm{~min}$ in RH $(p<0.001)$ (Figure 2, Table VI). The median length of stay in hospital after PDS was 8 days in TC $v s .4$ days in RH $(p<0.001)$ (Figure 3, Table VI). Median time to normal ADL was 12.5 days in TC $v s .7$ days in RH $(p<0.001)$. No significant differences were found in perioperative bleeding (Table VI).

Within eight weeks after surgery, there were $2.7 \%$ readmissions in TC vs. $1.5 \%$ in $\mathrm{RH}$ and $1.4 \%$ re-operations 


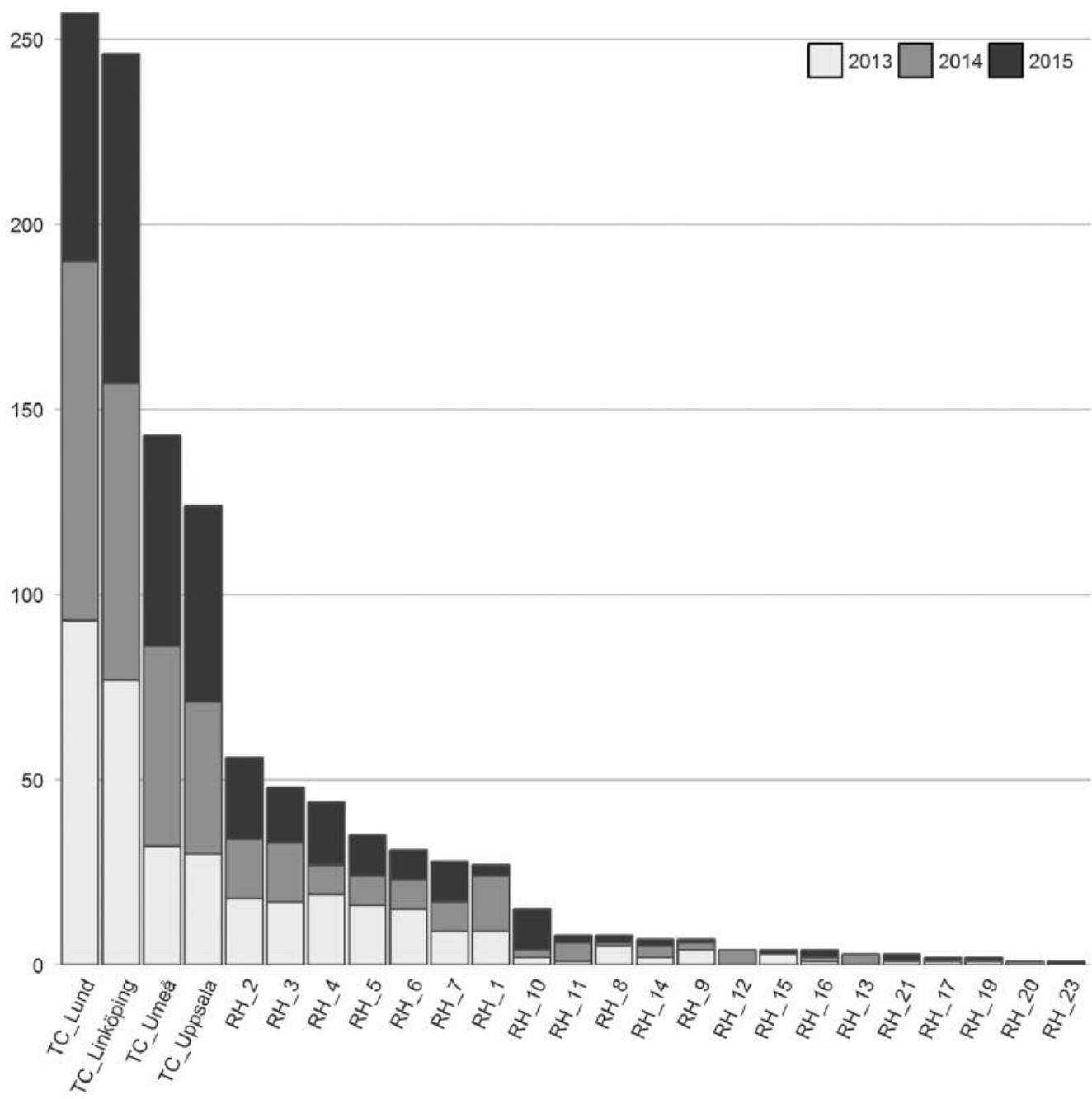

Figure 1. Total number of surgical procedures with curative intent for ovarian/tubal/peritoneal malignancy, including borderline tumors, registered in GynOp from 2013 to 2015.

in $\mathrm{TC} v s .1 .2 \%$ in $\mathrm{RH}$ with no significant differences between the two groups (Table VII). The overall patient response rate on the 8 -week questionnaire was $85 \%$.

Overall complication rates after surgery were higher in TC; $25.5 \%$ vs. $13.3 \%$ in RH $(p<0.001)$. The most common complication within eight weeks after surgery was infection, affecting twice as many patients in TC as in RH $(21.7 \%$ vs. $10.7 \%$ of RH patients $(p<0.001))$. Major complications were registered in $5.2 \%$ of TC patients $v s .2 .7 \%$ of RH patients (n.s.) (Table VII).

Table VIII lists specified major complications within 8 weeks after surgery. There were no significant differences among the specific major complications between TC and RH.

A logistic regression model was constructed to evaluate potential risk factors for severe postoperative complications including age, ASA classification, BMI, smoking, care level
(TC vs. RH), comorbidity, FIGO stage (IIIC-IV yes/no) and surgical treatment (PDS vs. IDS). In the whole patient population, FIGO stage IIIC-IV was the only factor associated with increased risk of severe complication, odds ratio $(\mathrm{OR})=2.38(1.11-5.45), p<0.05$. Limiting the logistic regression to the FIGO IIIC-IV population with the same variables as above revealed no significant risk factors.

The median waiting time for histopathological diagnosis after surgery was 22 days (interquartile range $(I Q R)=17-35)$ for TC and 24 days (IQR=15-35) for RH (n.s.).

\section{Discussion}

This population-based survey shows that $70 \%$ of surgery for ovarian malignancy, including borderline tumors, was performed in tertiary referral centers from 2013 through 
Table I. Patients' characteristics.

\begin{tabular}{|c|c|c|c|c|c|}
\hline & $\begin{array}{c}\text { Tertiary } \\
\text { Centers } \\
n=770 \\
\text { median }\end{array}$ & IQR & $\begin{array}{c}\text { Regional } \\
\text { Hospitals } \\
\mathrm{n}=338 \\
\text { median }\end{array}$ & IQR & $p$-Value \\
\hline Age & 64 & $55-71$ & 66 & $57-73$ & n.s. \\
\hline \multirow[t]{2}{*}{ BMI } & 25.2 & $22-29$ & 25.3 & $23-29$ & n.s. \\
\hline & $\%$ & $\mathrm{n}^{*}$ & $\%$ & $\mathrm{n}^{*}$ & \\
\hline Active smoking & $10 \%$ & $63 / 632$ & $12.6 \%$ & $28 / 223$ & n.s. \\
\hline ASA 3-4 & $10.3 \%$ & $77 / 745$ & $10.3 \%$ & $33 / 320$ & n.s. \\
\hline FIGO stage IIIC-IV & $51.4 \%$ & $396 / 770$ & $18.3 \%$ & $62 / 338$ & $<0.001$ \\
\hline RMI $>200$ & $83 \%$ & $392 / 471$ & $67 \%$ & $163 / 243$ & $<0.001$ \\
\hline \multicolumn{6}{|l|}{ Comorbidities: } \\
\hline Heart disease & $10.8 \%$ & $69 / 639$ & $13.2 \%$ & $31 / 234$ & n.s. \\
\hline Lung disease & $15.4 \%$ & $97 / 631$ & $20.5 \%$ & $47 / 229$ & n.s. \\
\hline Diabetes & $7.8 \%$ & $50 / 642$ & $7.7 \%$ & $18 / 235$ & n.s. \\
\hline Hypertension & $35.5 \%$ & $228 / 642$ & $36.6 \%$ & $86 / 235$ & n.s. \\
\hline
\end{tabular}

IQR, Interquartile range; n.s., non-significant; BMI, body mass index ASA, American Society of Anesthesiologists; FIGO, International Federation of Gynecology and Obstetrics; RMI, risk of malignancy index; *missing values are excluded from calculations.

Table II. FIGO stage in patients with invasive ovarian/tubal/peritoneal cancer.

\begin{tabular}{lccccc}
\hline & \multicolumn{2}{c}{ Tertiary Centers } & \multicolumn{2}{c}{ Regional Hospitals } & \\
\cline { 2 - 5 } FIGO stage* & $\mathrm{n}$ & $\%$ & $\mathrm{n}$ & $\%$ & $p$-Value \\
\hline I & 104 & $16 \%$ & 45 & $19.2 \%$ & n.s. \\
II & 27 & $4.1 \%$ & 8 & $3.4 \%$ & n.s. \\
IIIA+B & 49 & $7.5 \%$ & 13 & $5.6 \%$ & n.s. \\
IIIC & 319 & $48.9 \%$ & 48 & $20.5 \%$ & $<0.001$ \\
IV & 77 & $11.8 \%$ & 14 & $6 \%$ & $<0.05$ \\
X** & 76 & $11.7 \%$ & 106 & $45.3 \%$ & $<0.001$ \\
\hline Total & 652 & $100 \%$ & 234 & $100 \%$ & \\
\hline
\end{tabular}

*Borderline tumor excluded $(\mathrm{n}=219)$. Missing information on histopathology $(\mathrm{n}=3)$. $* *$ Stage $\mathrm{X}$ : Incomplete information on stage. FIGO, International Federation of Gynecology and Obstetrics; n.s., nonsignificant.

2015 in the regions of Sweden reporting to GynOp. No regional hospital had a case load above 20 ovarian cancer patients per year. In the RH group there will be some surgical procedures included with an unexpected finding of early stage malignancy, which may explain very few cases reported in several of RH. In stage IIIC-IV disease, $86 \%$ of the patients had their surgery in TC. RH reported 62 cases of stage IIIC-IV surgery. This number may be higher though
Table III. Surgery in FIGO stage IIIC-IV.

\begin{tabular}{lccccc}
\hline $\begin{array}{l}\text { Surgery in } \\
\text { stage IIIC-IV }\end{array}$ & \multicolumn{2}{c}{ Tertiary Centers } & \multicolumn{2}{c}{ Regional Hospitals } & $p$-Value \\
\cline { 2 - 5 } & $\mathrm{n}$ & $\%$ & $\mathrm{n}$ & $\%$ & \\
\hline PDS & 265 & $66.9 \%$ & 50 & $80.6 \%$ & $p<0.05$ \\
$\begin{array}{l}\text { No residual } \\
\text { tumor after }\end{array}$ & $144 / 265$ & $54 \%$ & $24 / 50$ & $48 \%$ & n.s. \\
$\begin{array}{l}\text { PDS } \\
\begin{array}{l}\text { IDS } \\
\text { No residual } \\
\text { tumor after }\end{array}\end{array}$ & 131 & $33.1 \%$ & 12 & $19.4 \%$ & $p<0.05$. \\
IDS & $53 \%$ & $3 / 12$ & $25 \%$ & n.s. \\
\hline Total & 396 & $100 \%$ & 62 & $100 \%$ & \\
\hline
\end{tabular}

FIGO, International Federation of Gynecology and Obstetrics; PDS, primary debulking surgery; IDS, interval debulking surgery; n.s., nonsignificant.

Table IV. Surgery in FIGO stage IIIC-IV in tertiary centers only.

\begin{tabular}{lcccccccccc}
\hline \multirow{2}{*}{$\begin{array}{l}\text { Surgery stage } \\
\text { IIIC-IV }\end{array}$} & & \multicolumn{4}{c}{ PDS } & \multicolumn{4}{c}{ IDS } \\
\cline { 5 - 11 } & Total & Total & \multicolumn{2}{c}{ No residual tumor } & Total & No residual tumor \\
\hline & $\mathrm{n}$ & $\mathrm{n}$ & $\%$ & $\mathrm{n}$ & $\%$ & $\mathrm{n}$ & $\%$ & $\mathrm{n}$ & $\%$ \\
\hline Linköping & 136 & 73 & $54 \%$ & $26 / 73$ & $36 \%$ & 63 & $46 \%$ & $32 / 63$ & $51 \%$ \\
Lund & 134 & 124 & $93 \%$ & $77 / 124$ & $62 \%$ & 10 & $8 \%$ & $6 / 10$ & $60 \%$ \\
Uppsala & 77 & 46 & $60 \%$ & $32 / 46$ & $70 \%$ & 31 & $40 \%$ & $21 / 31$ & $68 \%$ \\
Umeå & 49 & 22 & $45 \%$ & $9 / 22$ & $41 \%$ & 27 & $55 \%$ & $10 / 27$ & $37 \%$ \\
Total & 396 & 265 & $70 \%$ & $144 / 265$ & $54 \%$ & 131 & $33 \%$ & $69 / 131$ & $53 \%$ \\
\hline
\end{tabular}

Logistic regression analysis shows a significant difference between University Hospitals in patients with no residual tumor after PDS $(p<0.001)$ but not after IDS. FIGO, International Federation of Gynecology and Obstetrics; PDS, primary debulking surgery; IDS, interval debulking surgery.

as complete information on stage was not available in 2 out of $5 \mathrm{RH}$ patients and this group may include a considerable number of patients with advanced disease.

RMI (9) is a widely used algorithm for the preoperative assessment of pelvic masses and has been demonstrated to distinguish advanced ovarian cancer from benign ovarian masses with a sensitivity of $92 \%$ and a specificity of $82 \%$ (cut-off $=200) \quad(10,11)$. The Swedish Ovarian Cancer Treatment Guidelines (7) advocate that patients with RMI above 200 or suspicion of malignancy, according to ultrasound examination, are referred to a TC with surgeons specialized in gynecological oncology. In this study, RMI above 200 was more common among TC patients $(83 \%$ vs. $67 \%$ ). Still, many patients with preoperative RMI above 200 had their primary surgery in RH. New and improved 
Table V. Additional cytoreductive procedures in FIGO stage IIIC-IV surgery.

\begin{tabular}{|c|c|c|c|c|c|}
\hline \multirow[t]{2}{*}{ Cytoreductive procedure } & \multicolumn{2}{|c|}{$\begin{array}{l}\text { Tertiary Centers } \\
\mathrm{n}=396 \text { patients }\end{array}$} & \multicolumn{2}{|c|}{$\begin{array}{l}\text { Regional Hospitals } \\
\mathrm{n}=62 \text { patients }\end{array}$} & \multirow[b]{2}{*}{$p$-Value } \\
\hline & $\mathrm{n}$ & $\%$ & $\mathrm{n}$ & $\%$ & \\
\hline Resection of colon/rectum & 134 & $33.8 \%$ & 11 & $17.7 \%$ & $<0.05$ \\
\hline Splenectomy & 62 & $15.7 \%$ & 1 & $1.6 \%$ & $<0.01$ \\
\hline Small bowel resection & 33 & $8.3 \%$ & 6 & $9.7 \%$ & n.s. \\
\hline Resection of diaphragm & 29 & $7.3 \%$ & 0 & $0 \%$ & n.s. \\
\hline Cholecystectomy & 24 & $6.1 \%$ & 0 & $0 \%$ & n.s. \\
\hline Liver resection & 21 & $5.3 \%$ & 1 & $1.6 \%$ & n.s. \\
\hline Resection of stomach & 4 & $1 \%$ & 0 & $0 \%$ & n.s. \\
\hline Resection of bladder & 3 & $0.8 \%$ & 0 & $0 \%$ & n.s. \\
\hline Urinary tract deviation & 1 & $0.3 \%$ & 0 & $0 \%$ & n.s. \\
\hline Total number of patients with one or more procedures & 178 & $44.9 \%$ & 13 & $21 \%$ & $<0.001$ \\
\hline
\end{tabular}

FIGO, International Federation of Gynecology and Obstetrics; n.s., non-significant.

Table VI. Outcome of PDS in FIGO stage IIIC-IV.

\begin{tabular}{|c|c|c|c|c|c|}
\hline & \multicolumn{2}{|c|}{ Tertiary Centers } & \multicolumn{2}{|c|}{ Regional Hospitals } & \multirow[b]{2}{*}{$p$-Value } \\
\hline & median & range & median & range & \\
\hline Operation time $(\min )$ & 261.5 & $152.3-385.3$ & 148.5 & $104.5-193.5$ & $<0.001$ \\
\hline Estimated blood loss (ml) & 600 & $300-1200$ & 450 & $200-800$ & n.s \\
\hline Length of hospital stay (days) & 8 & 4-11 & 4 & 3-8 & $<0.001$ \\
\hline Time to normal ADL(days) & 12.5 & $7-20$ & 7 & $4-14$ & $<0.05$ \\
\hline
\end{tabular}

FIGO, International Federation of Gynecology and Obstetrics; PDS, primary debulking surgery; ADL, activity of daily living; n.s., non-significant.

diagnostic tools are implemented in clinical practice in recent years, i.e. risk of ovarian malignancy algorithm (ROMA) (12) and the ultrasound-based Simple Rules (13). However, if gynecologists at RH do not follow the guidelines and do not refer the patient to a TC when ovarian malignancy is suspected, there is little use for these algorithms and the patients are at risk of not receiving optimal treatment.

Improved survival at high volume hospitals ( $>20$ cases per year) with high-volume physicians ( $>10$ cases per year) has been shown by Bristow et al. (14) and is in consistence with a nation-wide Finnish study by Kumpulainen et al. (15) that shows better surgical outcome (as measured in amount of residual tumor) in high-volume hospitals. The Danish and Norwegian centralization of treatment to TCs has significantly improved outcome in advanced ovarian cancer $(16,17)$. A recent $S$ wedish article showed that centralized primary care of advanced ovarian and fallopian tube cancers increased complete cytoreduction, decreased time interval from PDS to chemotherapy, as well as improved relative survival (18). Rosen et al. state that every surgeon should
Table VII. Complications $<8$ weeks after surgery, all stages, borderline tumor patients included.

\begin{tabular}{lcccccc}
\hline & \multicolumn{2}{c}{$\begin{array}{c}\text { Tertiary } \\
\text { Centers } \\
\mathrm{n}=770\end{array}$} & & & \multicolumn{2}{c}{$\begin{array}{c}\text { Regional } \\
\text { Hospitals } \\
\mathrm{n}=338\end{array}$} \\
\cline { 2 - 3 } & $\mathrm{n}$ & $\%$ & & $\mathrm{n}$ & $\%$ & $p$-Value \\
\hline Re-operation & 21 & $2.7 \%$ & & 5 & $1.5 \%$ & \\
Re-admission & 11 & $1.4 \%$ & & 4 & $1.2 \%$ & n.s. \\
Major complications* & 40 & $5.2 \%$ & & 9 & $2.7 \%$ & n.s. \\
\hline
\end{tabular}

*see Table VIII for specific major complications. n.s., non-significant.

perform at least 30 procedures per year and that the team in the hospital should have at least 100 procedures per year in order to establish and maintain high quality in a specific surgical procedure (19). The published articles and this study indicate a need for further concentration of the treatment for 


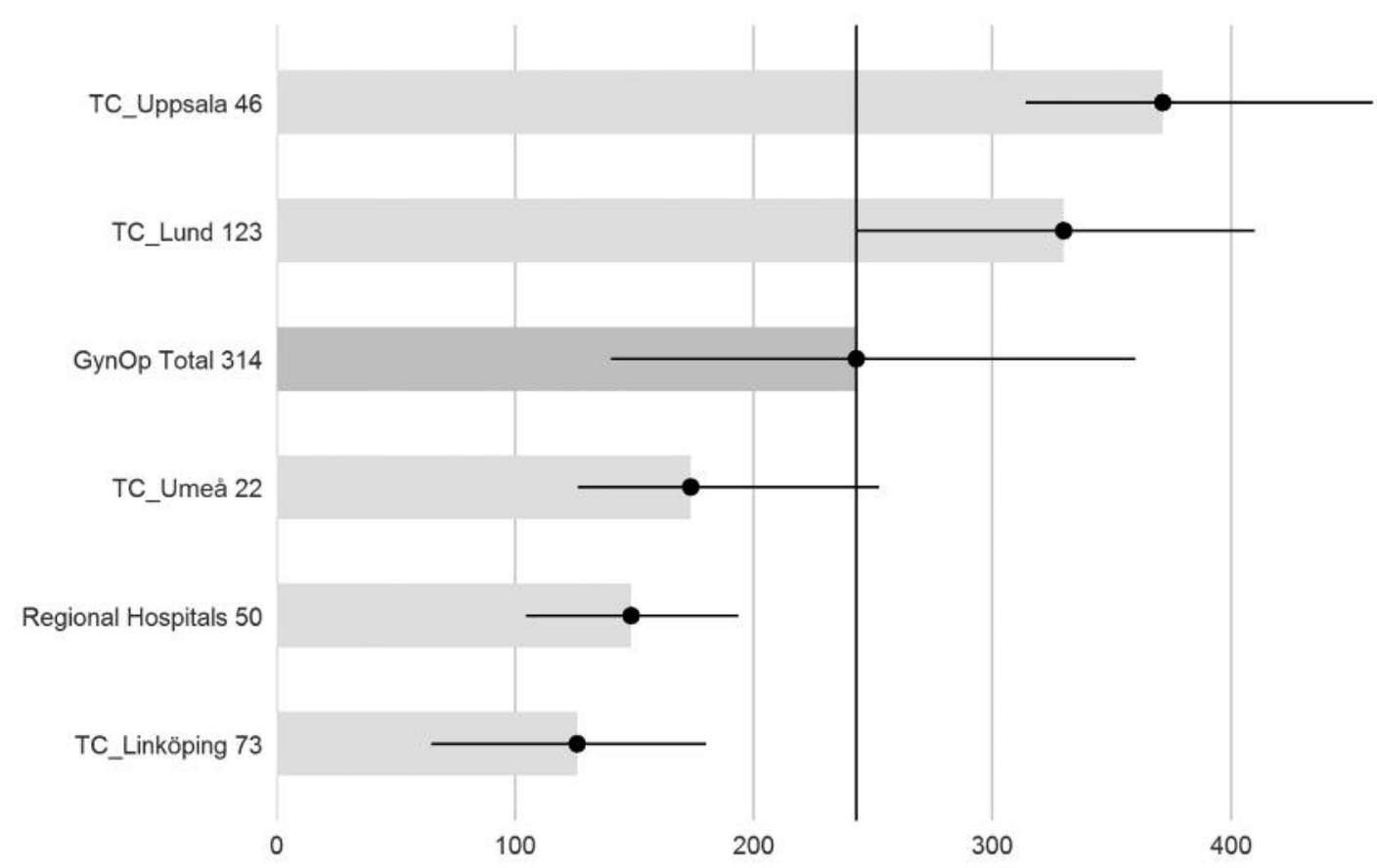

Figure 2. Operation time in the International Federation of Gynecology and Obstetrics (FIGO) stage IIIC-IV primary surgery.

Table VIII. Specified major complications $<8$ weeks after surgery, all stages, borderline tumor patients included.

\begin{tabular}{|c|c|c|c|c|c|}
\hline Complication & $\begin{array}{c}\text { Tertiary Centers } \\
\mathrm{n}=770\end{array}$ & $\%$ & $\begin{array}{l}\text { Regional Hospitals } \\
\mathrm{n}=338\end{array}$ & $\%$ & $p$-Value \\
\hline Urinary bladder & 1 & $0.1 \%$ & 0 & $0 \%$ & n.s \\
\hline Ureter & 2 & $0.3 \%$ & 1 & $0.3 \%$ & n.s \\
\hline Fascia rupture & 2 & $0.3 \%$ & 1 & $0.3 \%$ & n.s \\
\hline Bleeding/Hematoma/anemia & 10 & $1.3 \%$ & 1 & $0.3 \%$ & n.s \\
\hline Sepsis & 3 & $0.4 \%$ & 1 & $0.3 \%$ & n.s. \\
\hline Bowel complication* & 12 & $1.6 \%$ & 2 & $0.6 \%$ & n.s. \\
\hline Ileus & 13 & $1.7 \%$ & 4 & $1.2 \%$ & n.s. \\
\hline Respiratory problem or aspiration & 1 & $0.1 \%$ & 1 & $0.3 \%$ & n.s. \\
\hline Deep vein thrombosis & 5 & $0.6 \%$ & 3 & $0.9 \%$ & n.s. \\
\hline Major not specified complication & 9 & $1.2 \%$ & 3 & $0.9 \%$ & n.s. \\
\hline Total number of patients with one or more major complications & 40 & $5.2 \%$ & 9 & $2.7 \%$ & n.s. \\
\hline
\end{tabular}

*Bowel complication: perforation, anastomotic leak, abscess. n.s., non-significant.

ovarian cancer in Sweden. Optimally, all patients with suspected ovarian cancer should be referred to a tertiary high-volume center.

Opponents of aggressive surgery claim that tumor biology determines the surgical outcome and that aggressive surgery is associated with high morbidity. Contradictory, several studies have reported that aggressive surgery can make up for tumor biology (20). No residual tumor surgery is the goal in surgery for advanced ovarian cancer (5). Analysis of risk factors, such as age, performance status, nutrition and obesity, may allow the surgical team to triage patients at highest risk of serious morbidity to alternative primary treatment in multidisciplinary setting. Complete cytoreduction is achievable in up to $60 \%$ of patients with FIGO stage IIIC-IV ovarian cancer, although highly dependent on center expertise (20-22). Survival analysis has shown increased median survival after increasing surgical aggressiveness was instituted in a large center (21). In this 


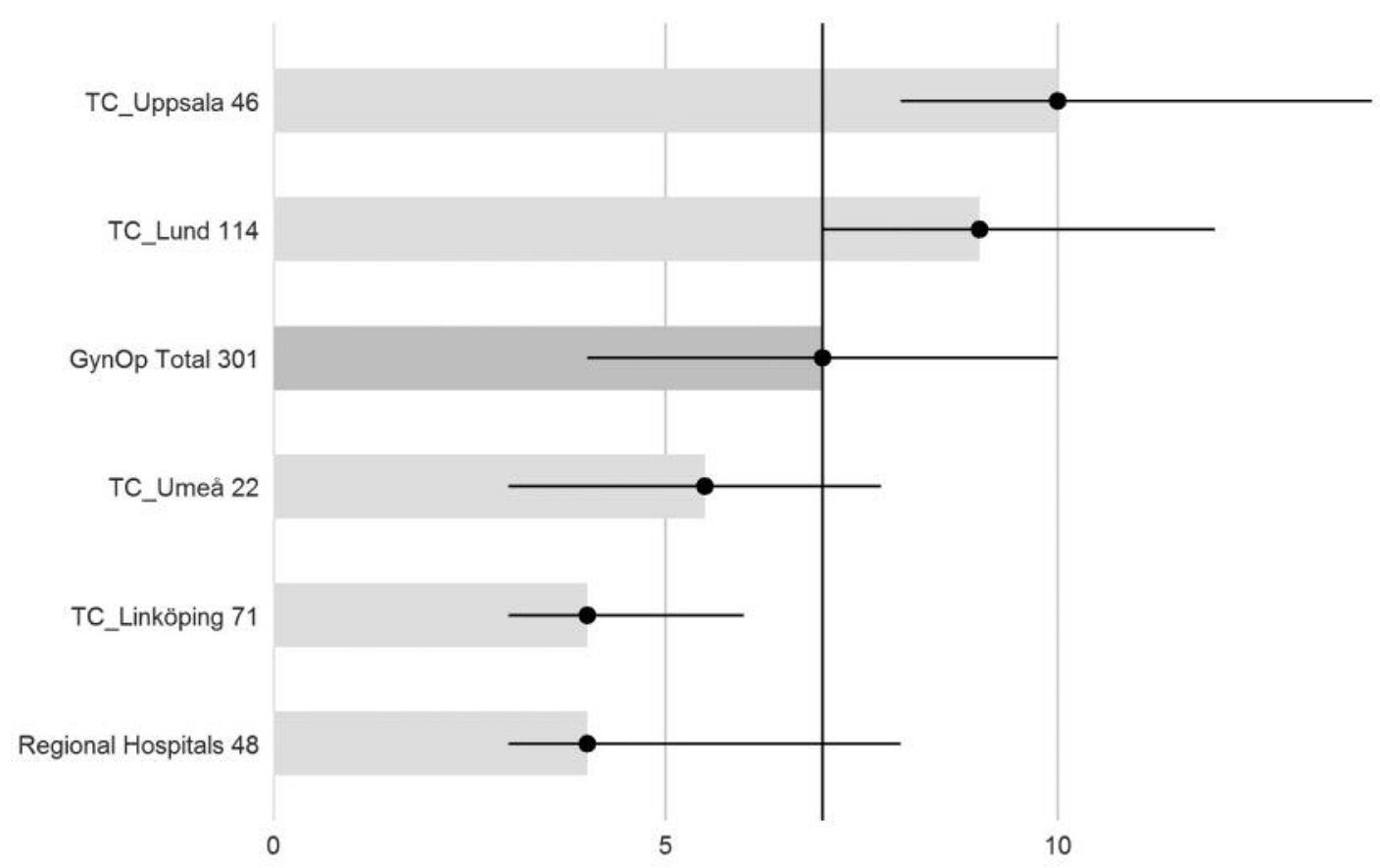

Figure 3. Postoperative days in hospital after International Federation of Gynecology and Obstetrics (FIGO) stage IIIC-IV primary surgery.

paper, the complete cytoreduction rate in TC patients was $54 \%$ in upfront PDS in advanced disease. A slightly lower rate of $48 \%$ was seen in $\mathrm{RH}$ patients, although the difference was non-significant, probably reflecting a low patient volume. We found considerable differences in selection for PDS versus IDS, as well as in debulking rates in the four TC. These differences cannot be due to patient selection in referral patterns. The national guidelines advocate neoadjuvant chemotherapy should be offered to patients with stage IIIC-IV with tumor extent in surgically inaccessible areas, old age or significant co-morbidity after discussion at multi-disciplinary conference. According to recommendations from the Society of Gynecologic Oncology and American Society of Clinical Oncology in 2016, "primary cytoreductive surgery is preferred if there is a high likelihood of achieving cytoreduction to $<1 \mathrm{~cm}$ (ideally to no visible disease) with acceptable morbidity" (23). The differences in patient selection for PDS and even in achieving complete debulking must be due to different strategies and policies at the different TCs that should be further analyzed and discussed in order to provide optimal and more equal preoperative assessment and treatment to patients throughout the country.

The operating time, as well as postoperative hospital stay and time to normal ADL, were longer for advanced stages PDS in TC and correlates well with the more frequent use of additional cytoreductive surgical procedures in TC. The importance of an aggressive surgical approach to improve survival in FIGO IIIC-IV disease, including extensive upper abdominal procedures to achieve complete debulking, is well-stablished $(5,24,25)$ and this is more often accomplished when the surgeon has gynecological oncological subspecialty training (26). The increased number of additional surgical procedures in TC in this study is likely to reflect more aggressive surgical efforts by surgeons with a higher degree of subspecialty training, including colorectal surgical competence. The most common additional debulking procedure is colon resection, as this is, in many cases, required for the optimal removal of the pelvic tumor, often performed as en bloc recto-sigmoid resection with a sigmoidrectal anastomosis or with a colostomy. When performed in TC by surgeons with gynecological oncology training, the complication rates are shown to be acceptably low with anastomotic leak in 3-6\% (27-29). Ideally, surgery for advanced disease should always involve at least one surgeon with gynecological oncological subspecialty training. In Sweden, there is an established 3-year subspecialty training program for gynecological oncological surgery since 1999.

The only significant risk factor for major complications after surgery was advanced stage disease (FIGO IIIC-IV) $(\mathrm{OR}=2.38)$ in our study. An increasing number of cytoreductive procedures is correlated to a higher rate of 
complications in the literature $(30,4,31)$ reporting higher complication rates in high-volume hospitals compared to hospitals with low- and intermediate-volume, but lower mortality rates for patients treated at high-volume hospitals, explained by higher ability to rescue patients with complications in high-volume hospitals. In accordance with these findings, we found more postoperative complications in TC patients, although major complications were uncommon and did non-significantly differ between TC and RH.

Waiting for definitive histopathological findings, diagnosis was long and did not differ for the two hospital groups. Several studies point to the importance of early initiation of chemotherapy after surgery. The paper by Mahner et al. (32) revealed that earlier recurrence and decreased overall survival were observed when chemotherapy was initiated more than 19 days after primary surgery. Hospitals with long time to histopathological diagnosis after surgery need to improve the logistics both to reduce the patient's time in uncertainty and to improve survival.

This study comprises of prospectively collected data covering all patients in the areas served by the hospitals reporting to the GynOp Registry, thus reducing the risk of selection bias. The patients' reported response rate was high $(85 \%)$ in the postoperative questionnaires that have been shown to provide more complete and thorough postoperative information than follow-up visits (33). There are limitations in the study. The number of referrals from the RH to TC could not be analyzed due to lack of information in the registry. Patients who never had any surgery were not included and, due to short follow-up, progression-free or overall survival could not be evaluated.

TCs perform more extensive surgery without increased frequency of major complications compared with RHs. Despite national and international recommendations, patients with suspicion of ovarian cancer still have primary surgery at RH. Four TCs performed more than 25 procedures per year with significant differences in patient selection for PDS, as well as achieving no residual tumor at surgical debulking. These differences need to be further analyzed and discussed. Published international papers and our data highlight the need for better preoperative assessment of patients with suspicion of ovarian cancer and concentration of the surgical treatment for ovarian cancer to TCs.

\section{Conflicts of Interest}

No conflicts of interest have been declared from any of the Authors.

\section{Funding}

The study was supported by funds from the Swedish Cancer Foundation.

\section{Acknowledgements}

The Authors thank the Swedish National Quality Registry of Gynecological Surgery (GynOp Registry) and the Swedish Association of Local Authorities and Regions (SKL), which financially support the GynOp Registry. All Authors have approved the final version of the manuscript.

\section{References}

1 The Swedish National Board of Health and Welfare: Cancer incidence in Sweden 2014. htpp://www.socialstyrelsen.se, 2014.

2 Cancer incidence, Mortality, Prevalence and Survival in the Nordic Countries version 7.3 htpp://www.ancr.nu, 2016.

3 Bristow RE and Chi DS: Platinum-based neoadjuvant chemotherapy and interval surgical cytoreduction for advanced ovarian cancer: A meta-analysis. Gynecol Oncol 103(3): 1070-1076 2006.

4 Gerestein CG, Damhuis RA, Burger CW and Kooi GS: Postoperative mortality after primary cytoreductive surgery for advanced stage epithelial ovarian cancer: a systematic review. Gynecol Oncol 114(3): 523-527, 2009.

5 Aletti GD, Dowdy SC, Gostout BS, Jones MB, Stanhope CR, Wilson TO, Podratz KC and Cliby WA: Aggressive surgical effort and improved survival in advanced-stage ovarian cancer. Obstet Gynecol 107(1): 77-85, 2006.

6 du Bois A, Rochon J, Pfisterer J and Hoskins WJ: Variations in institutional infrastructure, physician specialization and experience, and outcome in ovarian cancer: A systematic review. Gynecol Oncol 112(2): 422-436, 2009.

7 Regional Cancer Centrum. (National Guidelines for Ovarian Cancer) Nationella Vårdprogrammet för Äggstockscancer. Regionala Cancercentrum i Samverkan, 2015.

8 The Swedish National Board of Health and Welfare. Public Comparisons 2014: Cancertreatment. 2014.

9 Jacobs I, Oram D, Fairbanks J, Turner J, Frost C and Grudzinskas JG: A risk of malignancy index incorporating CA 125, ultrasound and menopausal status for the accurate preoperative diagnosis of ovarian cancer. British J Obstet Gynecol 97(10): 922-929, 1990.

10 Hakansson F, Hogdall EV, Nedergaard L, Lundvall L, Engelholm SA, Pedersen AT, Hartwell D and Hogdall C: Danish 'pelvic mass' ovarian cancer. Risk of malignancy index used as a diagnostic tool in a tertiary centre for patients with a pelvic mass. Acta Obstet Gynecol Scand 91(4): 496-502, 2012.

11 Tingulstad S, Hagen B, Skjeldestad FE, Onsrud M, Kiserud T, Halvorsen $\mathrm{T}$ and Nustad K: Evaluation of a risk of malignancy index based on serum CA125, ultrasound findings and menopausal status in the pre-operative diagnosis of pelvic masses. British J Obstet Gynecol 103(8): 826-831, 1996.

12 Moore RG, Jabre-Raughley M, Brown AK, Robison KM, Miller MC, Allard WJ, Kurman RJ, Bast RC and Skates SJ: Comparison of a novel multiple marker assay $v s$. the risk of malignancy index for the prediction of epithelial ovarian cancer in patients with a pelvic mass Am J Obstet Gynecol 203(3): 228 e221-226, 2010.

13 Timmerman D, Ameye L, Fischerova D, Epstein E, Melis GB, Guerriero S, Van Holsbeke C, Savelli L, Fruscio R, Lissoni AA, Testa AC, Veldman J, Vergote I, Van Huffel S, Bourne T and Valentin L: Simple ultrasound rules to distinguish between benign and malignant adnexal masses before surgery: prospective validation by IOTA group. BMJ 341: c6839, 2010. 
14 Bristow RE, Palis BE, Chi DS and Cliby WA: The National Cancer Database report on advanced-stage epithelial ovarian cancer: Impact of hospital surgical case volume on overall survival and surgical treatment paradigm. Gynecol Oncol 118(3): 262-267, 2010.

15 Kumpulainen S, Sankila R, Leminen A, Kuoppala T, Komulainen M, Puistola U, Hurme S, Hiekkanen H, Makinen J and Grenman S: The effect of hospital operative volume, residual tumor and first-line chemotherapy on survival of ovarian cancer - a prospective nation-wide study in Finland. Gynecol Oncol 115(2): 199-203, 2009.

16 Fagö-Olsen CL, Høgdall C, Kehlet H, Christensen IJ and Ottesen B: Centralized treatment of advanced stages of ovarian cancer improves survival: A nationwide Danish survey. Acta Obstet Gynecol Scand 90(3): 273-279, 2011.

17 Paulsen T, Kjaerheim K, Kaern J, Tretli S and Trope C: Improved short-term survival for advanced ovarian, tubal, and peritoneal cancer patients operated at teaching hospitals. International journal of gynecological cancer 16(Suppl 1): 11-17, 2006.

18 Dahm-Kahler P, Palmqvist C, Staf C, Holmberg E and Johannesson L: Centralized primary care of advanced ovarian cancer improves complete cytoreduction and survival - A population-based cohort study. Gynecol Oncol 142(2): 211-216, 2016.

19 Rosen M, Lawrence M, Lawrence M and Nilsson M: High volume is necessary for high quality in health care. Lakartidningen 112, 2015.

20 Chang SJ, Bristow RE, Chi DS and Cliby WA: Role of aggressive surgical cytoreduction in advanced ovarian cancer. J Gynecol Oncol 26(4): 336-342, 2015.

21 Harter P, Muallem ZM, Buhrmann C, Lorenz D, Kaub C, Hils R, Kommoss S, Heitz F, Traut A and du Bois A: Impact of a structured quality management program on surgical outcome in primary advanced ovarian cancer. Gynecol Oncol 121(3): 615619, 2011.

22 Kang S, Jong YH, Hwang JH, Lim MC, Seo SS, Yoo CW and Park SY: Is neo-adjuvant chemotherapy a "waiver" of extensive upper abdominal surgery in advanced epithelial ovarian cancer? Ann Surg Oncol 18(13): 3824-3827, 2011.

23 Wright AA, Bohlke K, Armstrong DK, Bookman MA, Cliby WA, Coleman RL, Dizon DS, Kash JJ, Meyer LA, Moore KN, Olawaiye AB, Oldham J, Salani R, Sparacio D, Tew WP, Vergote I and Edelson MI: Neoadjuvant chemotherapy for newly diagnosed, advanced ovarian cancer: Society of Gynecologic Oncology and American Society of Clinical Oncology Clinical Practice Guideline. Gynecol Oncol 143(1): 3-15, 2016.

24 Chang SJ, Hodeib M, Chang J and Bristow RE: Survival impact of complete cytoreduction to no gross residual disease for advanced-stage ovarian cancer: A meta-analysis. Gynecol Oncol 130(3): 493-498, 2013
25 Chi DS, Eisenhauer EL, Zivanovic O, Sonoda Y, Abu-Rustum NR, Levine DA, Guile MW, Bristow RE, Aghajanian C and Barakat RR: Improved progression-free and overall survival in advanced ovarian cancer as a result of a change in surgical paradigm. Gynecol Oncol 114(1): 26-31, 2009.

26 Engelen MJ, Kos HE, Willemse PH, Aalders JG, de Vries EG, Schaapveld M, Otter R and van der Zee AG: Surgery by consultant gynecologic oncologists improves survival in patients with ovarian carcinoma. Cancer 106(3): 589-598, 2006.

27 Mourton SM, Temple LK, Abu-Rustum NR, Gemignani ML, Sonoda Y, Bochner BH, Barakat RR and Chi DS: Morbidity of rectosigmoid resection and primary anastomosis in patients undergoing primary cytoreductive surgery for advanced epithelial ovarian cancer. Gynecol Oncol 99(3): 608-614, 2005.

28 Obermair A, Hagenauer S, Tamandl D, Clayton RD, Nicklin JL, Perrin LC, Ward BG and Crandon AJ: Safety and efficacy of low anterior en bloc resection as part of cytoreductive surgery for patients with ovarian cancer. Gynecol Oncol 83(1): 115-120, 2001.

29 Peiretti M, Bristow RE, Zapardiel I, Gerardi M, Zanagnolo V, Biffi R, Landoni F, Bocciolone L, Aletti GD and Maggioni A: Rectosigmoid resection at the time of primary cytoreduction for advanced ovarian cancer. A multi-center analysis of surgical and oncological outcomes. Gynecol Oncol 126(2): 220-223, 2012.

30 Aletti GD, Santillan A, Eisenhauer EL, Hu J, Aletti G, Podratz $\mathrm{KC}$, Bristow RE, Chi DS and Cliby WA: A new frontier for quality of care in gynecologic oncology surgery: Multiinstitutional assessment of short-term outcomes for ovarian cancer using a risk-adjusted model. Gynecol Oncol 107(1): 99106, 2007.

31 Wright JD, Herzog TJ, Siddiq Z, Arend R, Neugut AI, Burke WM, Lewin SN, Ananth CV and Hershman DL: Failure to rescue as a source of variation in hospital mortality for ovarian cancer. J Clin Oncol 30(32): 3976-3982, 2012.

32 Mahner S, Eulenburg C, Staehle A, Wegscheider K, Reuss A, Pujade-Lauraine E, Harter P, Ray-Coquard I, Pfisterer J and du Bois A: Prognostic impact of the time interval between surgery and chemotherapy in advanced ovarian cancer: Analysis of prospective randomised phase III trials. Eur J Cancer 49(1): 142149, 2013.

33 Ladfors MB, Lofgren ME, Gabriel B and Olsson JH: Patient accept questionnaires integrated in clinical routine: a study by the Swedish National Register for Gynecological Surgery. Acta Obstet Gynecol Scand 81(5): 437-442, 2002.

Received February 24, 2017

Revised March 12, 2017

Accepted March 14, 2017 